Proceeding

\title{
Holistic recovery
}

\section{Proceeding}

When we asked 150 substance abuse counselors what the four behaviors that account for the majority of chronic diseases and premature deaths were, they immediately shouted out the correct answers: "Smoking! Alcohol abuse! Unhealthy diet! Not enough exercise!" But when we asked why these four behaviors were so critical to our health and well-being, there were no good guesses. The answer is that those four behaviors are fundamental processes of life: breathing, drinking, eating, and moving. If we breathe toxins, we threaten our bodies. If we drink alcohol to toxic levels, we do damage to our mind and bodies. If we eat toxins, we seriously risk our wellbeing. And, if we don't move it, move it, move it enough, we don't move enough toxins out of our bodies. Over $90 \%$ of all adults in the U.S. have two or more of those high risk and high cost behaviors. The majority of individuals who abuse alcohol and other drugs have all four. Individuals suffering from substance abuse or serious mental illness die from the same behaviors as most of us, but they die 10years sooner. No wonder the Substance Abuse and Mental Health Service Agency Samsha ${ }^{1}$ has identified Holistic Recovery as the best practice for these populations that SAMSHA serves. The problem is that most substance abuse and mental health counselors and therapists do not know how to effectively and efficiently change these most damaging multiple behaviors. Furthermore, our health care systems do not treat those threats seriously.

We once asked 35 medical directors of the largest U.S. health plans about the quantity and quality of behavior medicine that their primary care practices provided to help patients make behavior changes that would prevent or manage chronic disease. Their answer? The quantity is typically zero, and the quality is typically awful. But what about a fifth big threat? What is the most common condition that drives people to breathe, drink, or eat at toxic levels? Professionals typically guess stress-and they are right. But we encourage them to think of distress. Times of anxiety, depression, anger, and boredom stress our abilities to cope. These times are like fevers: they signal that something is wrong with our emotional, mental, or physical well-being. So, how do average Americans cope with different types of distress? We smoke more cigarettes, drink more alcohol, and eat more comfort and junk foods, and collapse on the couch. Why is the fifth threat so critical to our health and happiness? This behavior is also fundamental to another domain of well-being necessary for a happy life: feeling.

We need to make clear that what we call the "Big 5" are not the only behaviors that threaten our health and happiness. Not enough sleep, too much sun exposure, discontinuing prescribed medications, are other examples of a seemingly endless list of behaviors that can threaten our physical and emotional health. The principles for changing behavior have been found to apply to changing more than fifty different behaviors. So, if you have a different (or another) behavior that needs attention, you need not worry. The strategies you can learn will help you address your needed behavior change. The principles followed as one progresses through the Stages of Change from Precontemplation (not ready) to Contemplation (getting ready) to Preparation (ready) to Action and Maintenance to remove one bad

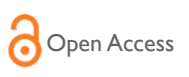

CrossMark

Volume 4 Issue 4 - 2017

\section{James O Prochaska, Janice M Prochaska \\ Cancer Prevention Research Center, University of Rhode Island, USA}

Correspondence: James O Prochaska, Cancer Prevention Research Center, University of Rhode Island, USA, Email jmprochaska@prochange.com

Received: July 15, 2017| Published: August 03, 2017 habit that can be used to remove multiple bad habits. By removing unhealthy habits the great deadeners of life -- we can live longer lives, fuller lives, and better lives. We don't have to wait for a crisis, and we certainly don't have to wait until we have hit bottom before we will be moved to change.

The most common presentations to professionals and public that we have been delivering across the country have been on Holistic Recovery defined by Samsha ${ }^{1}$ as the process of change through which individuals improve their health and wellness, live a self-directed life, and strive to reach their full potential. Our new book, Changing to Thrive, ${ }^{2}$ includes chapters that are like mini guides that can take professionals and the public through the Stages of Change for each of the Big 5 behaviors. In Changing to Thrivewe not only teach how to change a high risk behavior, we also show how many more benefitsthan you have imagined possible can come from changing a single behavior. We provide guidance on how to change multiple behaviors with innovative strategies that produce the synergy that allows individuals to get back more change from their time and efforts than if they were trying to change each behavior separately. When we wrote Changing forGood, ${ }^{3}$ we were working from a model of health that was defined as the absence of disease and the absence of risks for disease. With new research, we now know that this is an incomplete model of health and humanity because it tells us what should be absent from our lives, not what needs to be present.

Today, we offer much more. we actually help one to gain greater happiness. "Happiness" is the single best word that captures the concept of well-being. Just as there are a small number of behaviors that account for high percentages of chronic disease and premature death, there are a small number of elements that account for much of the happiness in our lives. These include:
i. physical well-being
ii. emotional well-being
iii. financial well-being 


\section{iv. social well-being}

v. purpose, which reflects your most valued passions

One of our scientific and professional strategies continues to be to keep raising the bar to produce best practices with higher impacts. We and our colleagues were most surprised by the huge impact our multiple behavior change strategies had on a large population of 4,000 with more than four risk behaviors and almost four chronic conditions. These risks included addictive, affective, energy balance, and other risks with $70 \%$ overweight or obese. We were able to reduce multiple risk behaviors in a majority of these individuals. Furthermore, their health improved significantly; their happiness improved even more; and their functioning at home and work improved. What we were most concerned about was that the majority of the 4,000 individuals from 39 states in this project were suffering or struggling in life with only a minority thriving. The only time we saw such a profile in the U.S. was after the economic crash of 2008. It took the federal government 12 months and $\$ 700$ billion dollars to help the majority to be thriving again. With just a total of 60 minutes on the phone or online we helped the majority of our participants to be thriving within six months. So many people in need of recovery not only need help with the Big 5 risks to their health. They also need help with enhancing multiple domains of well-being. Our most prized goal for our new book is to help professionals and the public apply principles of change that can dramatically reduce suffering and struggling while increasing thriving as a special way to recover.

In the process of helping individuals remove the biggest threats to their health, we can also help them fill and fulfill more of their lives with what matters most to them. Twenty years ago, we could not imagine making such claims. We also could, not imagine that we would be blessed with a continuing series of breakthroughs in the science and practice of behavior change. We feel fortunate to have the opportunity to share these innovations with you and to help you break out of chronic, high-risk behavior patterns, or bad or unhealthy habits that might he getting in the way of your happiness and well-being. Our mission has been to help as many people as possible enhance their health and well -being. If they learn how to change the behaviors that most threaten their health and happiness, they can change to thrive so that you can live healthier, longer, better and fuller lives. ${ }^{2}$

Bios james o prochaska: James O. Prochaska is the Director of the Cancer Prevention Research Center and Professor of Clinical and Health Psychology at the University of Rhode Island and developer of the Stages of Change Model. He is the first psychologist to win the Medal of Honor for Research from the American Cancer Society. He has recently been recognized as one of the top three most preeminent clinical psychologists. He is the founder of Pro-Change Behavior Systems, Inc.

Janice M prochaska: One of the most published authors in the field of social work, Janice M Prochaska led research and development teams for health behavior and organizational change programs as the CEO at Pro-Change Behavior Systems, Inc. from 1997-2015. Her collaborations include applying the Model to cutting edge issues like simultaneously reducing multiple risk behaviors and enhancing multiple domains of well-being, healthy weight management in children and adults, preventing bullying, keeping individuals out of trouble with the law, and advancing careers with populations like women scientists. Dr. Prochaska, who holds an adjunct position at URI, earned her Master's in Social Work from Wayne State University and her Ph.D. in Social Work Administration and Policy from Boston College. In 2003, she was recognized with an Achievement Award by the Providence Business News as one of the Outstanding Leaders in New England.

\section{Acknowledgments}

None.

\section{Conflicts of interest}

Author declares there are no conflicts of interest.

\section{Funding}

None.

\section{References}

1. Samsha. Working Definition of Recovery. 2011.

2. Prochaska, JO, Prochaska JM. Changing to Thrive: Using the Stages of Change to Overcome the Top Threats to YourHealth and Happiness. $M N$ Hazelden Publishing, Center City, USA. 2016.

3. Prochaska JO, Norcross JC, DiClemente CC. Changing for good: The Revolutionary Program that Explains the SixStages of Change and Techers you How to Free Yourself from Bad Habits.New York, USA. 1994. 